\title{
Clinical, genetic and microbiological characterization of pediatric patients with cystic fibrosis in a public Hospital in Ecuador
}

Yazmina Lascano-Vaca', Esteban Ortiz-Prado ${ }^{2 *}$ (D), Lenin Gomez-Barreno ${ }^{2}$, Katherine Simbaña-Rivera², Eduardo Vasconez ${ }^{2}$, Alexander Lister ${ }^{3}$, María Emilia Arteaga-Espinosa ${ }^{4}$ and Geovanny F. Perez ${ }^{5}$

\begin{abstract}
Background: To carry out a complete clinical, pathological, genetic and microbiological characterization of pediatric patients with molecular confirmed cystic fibrosis (CF) attending the Carlos Andrade Marín Hospital (HCAM) within the study period.

Methods: A cross-sectional analysis of the pediatric population with a confirmed diagnosis of CF disease who attended HCAM, one of the largest tertiary-level hospitals in Ecuador, between 2017 and 2018 was performed. All demographic, clinical and genetic variables were obtained from the electronic medical records (EMR) stored by the hospital.

Results: Forty seven patients with CF were included in the study. Gender distribution was similar between male $(48.9 \%, n=23)$ and female patients $(51.1 \%, n=24)$. The Tiffeneau-Pinelli index (FEV $/ / F V C)$ changed significantly after nine months post-diagnosis $(85.55 \pm 13.26 ; p<0.05)$. The most common pathogenic genetic variants were F508del, found in 52.78\% of the cohort $(n=19)$; H609R, found in 36.11\% ( $n=13) ; \mathrm{g} .204099 \mathrm{~A}>\mathrm{C}$, found in $14.1 \%(n=7)$, followed by G85E and the N1303K with $11.11 \%(n=3)$ each.
\end{abstract}

Conclusions: To our best knowledge, this is the first study exploring the clinical, genetic and bacteriological profile of CF's patients in Ecuador. Within the cohort of patients, an important and unique genetic feature was characterized by the presence of the g.204099A > C and the C.206359C > A homozygous polymorphism as well as the presence of the H609R variant, a mutation only reported among Ecuadorians.

Keywords: Cystic fibrosis, Epidemiological analysis, Clinical characterization

\section{Background}

Cystic fibrosis (CF) is an autosomal recessive disorder caused by a variant in a gene located on the long arm of chromosome 7. The affected gene is the cystic fibrosis transmembrane regulator (CFTR), which when mutated

\footnotetext{
* Correspondence: e.ortizprado@gmail.com

${ }^{2}$ One Health Research Group, Universidad de Las Americas, José Queri and Av. de los Granados, Quito, Ecuador

Full list of author information is available at the end of the article
}

produces an abnormal production of the cystic fibrosis transmembrane regulator protein [1-3]. This condition affects many organ systems within the body [4-7], with a clinical presentation potentially including progressive obstructive lung disease, bronchitis, bronchiectasis, mild to severe pancreatic insufficiency, malnutrition and recurrent sinusitis, with infertility also being common in men $[7,8]$.

C C The Author(s). 2020 Open Access This article is licensed under a Creative Commons Attribution 4.0 International License, which permits use, sharing, adaptation, distribution and reproduction in any medium or format, as long as you give appropriate credit to the original author(s) and the source, provide a link to the Creative Commons licence, and indicate if changes were made. The images or other third party material in this article are included in the article's Creative Commons licence, unless indicated otherwise in a credit line to the material. If material is not included in the article's Creative Commons licence and your intended use is not permitted by statutory regulation or exceeds the permitted use, you will need to obtain permission directly from the copyright holder. To view a copy of this licence, visit http://creativecommons.org/licenses/by/4.0/ The Creative Commons Public Domain Dedication waiver (http://creativecommons.org/publicdomain/zero/1.0/) applies to the data made available in this article, unless otherwise stated in a credit line to the data. 
CF has become an important public health problem. It has a great impact in terms of healthcare-related costs and on the years of potential life lost (PYLL), resulting in an economic burden for health systems globally [912]. CF is one of the most common and lethal genetic diseases, affecting an estimated 70,000 patients from all ethnic groups worldwide [8]. The incidence ranges from $1: 2000$ to $1: 35,000$ in newborns, representing more than 1000 new cases of CF that are diagnosed each year before the age of two [7, 8, 12, 13]. Universal newborn screening and early treatment have markedly improved median survival rates in high-income countries (HIC) in comparison to low- and middle-income countries (LMIC) [12, 14-16]. In countries like the United States, Canada and some European countries, average survival curves have improved in the last 30 years, with some patients reaching life expectancies of 50 years or more [17-20]. On the other hand, patients from LMICs often have poorer health outcomes, living on average 10 to 15 years less than individuals with CF from HICs [15, 20, 21]. Zolin et al. revealed that mortality among younger patients (under 18 years of age) reaches $1.3 \%$ in LMIC and less than $0.6 \%$ in high-middle income countries (HMICs) [22]. In LatinAmerica, most of the children presenting with related symptoms are misdiagnosed or not diagnosed at all, usually leading to early deaths before reaching the first five years of age [16]. In Latin America, CF's incidence ranges from 1:6000 to 1:12,000 per every live birth. For instance, Mexico has an incidence of 1:9000, Uruguay at 1:9600 and in Argentina an estimation of 1:6573 per every live birth [23].

In Ecuador, there has been few academic studies on CF. An analysis from Valle et al. [24] determined for the first time, the incidence of the disease in the country at 1:11,252 live births [24]. Although there are a few reports of CF in Ecuador, there are no detailed reports including diagnostic, microbiologic and genetic analysis, as well as pulmonary function data, as recommended by international guidelines such as the North American Cystic Fibrosis Foundation [25-27].

The objective of this study was to conduct a complete clinical, pathological, genetic and microbiological characterization of pediatric patients with molecular confirmed CF attending the Carlos Andrade Marín Hospital within the study period.

\section{Methods}

\section{Study design}

A cross-sectional study of pediatric patients with confirmed cystic fibrosis from the tertiary-level hospital, Carlos Andrade Marín (HCAM), was performed. The data included information from all available aspects of the patients' charts recorded between June 2017 to July 2018.

\section{Setting}

This study was conducted in the largest capacity hospital of the Social Security Institute (IESS). The HCAM has a clinic system with a multidisciplinary team specialized in management of CF, who receive referrals and admissions from the nearby provinces and cities. The hospital is located in Quito, the capital of Ecuador. During the study period, the clinic received 81 patients, pediatric and adult, with diagnosis of cystic fibrosis.

\section{Participants}

A total of 48 individuals aged 16 or younger with a confirmed diagnosis of cystic fibrosis (positive sweat test accompanied a pathological genetic variant report) were approached for inclusion in this study. One child whose parents did not consent to participate was excluded from the study, leading to 47 pediatric patients being included for analysis. It is important to emphasize that there were two pairs of siblings within the study.

\section{Treatment}

Throughout the study, all patients had the same standard treatment protocol that included: respiratory therapy with inhaled Dornase Alfa and hypertonic saline twice daily, respiratory physiotherapy with prolonged slow expiratory and forced expiratory techniques, and digestive enzymes according to weight to all patients with stool elastase less than 200. For patients with Pseudomonas bacteria colonization, tobramycin through inhalation was administered twice daily for 28 days. All additional interventions due to exacerbations were described in the results section.

\section{Ethical considerations}

Informed consent was obtained from every patient and their parents or their legal representatives after disclosing the full purpose of the study. All data were anonymized before further analysis through assigning a study reference number between one and forty-seven, allocated upon patient presentation. The local Institutional Review Board at HCAM approved this study in 2017.

\section{Data}

Demographic, clinical and analytic variables were obtained by reviewing electronic medical records (EMR) from all the patients included in the study in a 12month period. Demographic information was obtained for analysis, which included the patient's age, gender, ethnicity, place of residence and educational attainment level. Clinical parameters included family and personal medical history, respiratory/gastrointestinal symptomatology and Shwachman - Kulczycki (SK) disease severity score. The SK scores were considered in the categories of 'excellent' (86-100), 'good' (71-85), 'mild' 
(56-70), 'moderate' (41-55), or 'severe' disease severity $(\leq 40)$. Follow-up was conducted through ongoing scheduled clinician appointments at the hospital. Analytical tests were performed to evaluate pulmonary function using a Spirometer (CareFusion Germany 234 GmbH software) following the ATS/ERS standard criteria. Forced Vital Capacity (FVC), Forced Expiratory Volume in One Second $\left(\mathrm{FEV}_{1}\right)$ and $\mathrm{FEV}_{1} / \mathrm{FVC}$ measurements were used for statistical analysis. In addition, microbiological cultures and sensitivity tests were conducted in every patient. Those children under five years of age had deep throat cultures taken, and for children over five years of age, sputum samples were used to evaluate microbiological colonization. Finally, all patients were analyzed for CFTR gene variants by polymerase chain reaction (PCR) and Sanger sequencing by cycling temperature capillary electrophoresis of a panel of 10 specific CFTR common variants for the Ecuadorian population. Also, 13 patients had CFTR full-length sequencing analysis, which was processed in the United States. Since the full-length sequencing tests were not available in Ecuador and the exportation of the samples were not covered by the public insurance, some patients were not able to obtain the resources to proceed with the full sequence.

\section{Statistical analysis}

Data were analyzed using the software SAS (Version 9.3; SAS Institute Inc., Cary, NC, USA). Patients were categorized into four subgroups: < 5 years, 5 to 9 years, 10 to 14 years old and $\geq 15$ years old. Descriptive statistics, such as simple frequencies and means, were used to calculate demographic distribution, clinical findings, cultures and sensitivity of germs, and genetic profiles. For pulmonary function, statistics calculated were a parametric test with Shapiro-Wilk formula and a paired $t$ test for related samples to evaluate the deterioration of pulmonary function. Statistical significance was determined at $\mathrm{p} \leq 0.05$.

\section{Results}

\section{Demographics}

Out of 48 pediatric patients that fulfilled the inclusion criteria, 47 were included since one patient withdraw the consent. The sex distribution corresponded to $24 \mathrm{fe}-$ males and 23 males. Age distribution at study period demonstrated that $27.7 \%(n=13)$ were under five years, $23.4 \%(n=11)$ were between five and nine years, $31.9 \%$ $(n=15)$ were between 10 and 14 years and $17.0 \%(n=8)$ of patients were 15 years or older, with a median age of 9.2 years ( $\mathrm{SE}+/-4.98$ years). The maximum age was 16 years. In the case of age of diagnosis referred by parents, it was found an age of 5.3 years (SE $+/-5.26$ years). Overall, $89.4 \%(n=42), 6.4 \%(n=3)$ and $4.3 \%(n=2)$ of patients were auto-identified as mixed race, white and indigenous, respectively.

\section{Clinical variables}

A total of $41(87.2 \%)$ children were referred to the hospital for diagnosis due to persistent respiratory symptoms (cough, recurrent pneumonia, dyspnea on exertion and chest pain). Six patients (12.8\%) were referred with persistent gastrointestinal symptoms (including abdominal distention, increased frequency of stools, flatulence or steatorrhea). These symptoms were present at the time of diagnosis, and it was because of these symptoms the individuals had been referred to the hospital for diagnosis. Four patients $(8.5 \%)$ had positive family history of the disease (Table 1 ).

Nutritional evaluation included body mass index (BMI) and percentile tables. Malnutrition was found in $25.5 \%(n=12)$ of children with the females showing a median BMI of $17.4 \mathrm{~kg} / \mathrm{m}^{2}$ (percentile $42 \mathrm{nd}$; $\mathrm{z}$-score 0.42 ) and males showing an average BMI of $15.8 \mathrm{~kg} / \mathrm{m}^{2}$ (percentile 28th; z-score - 0.87). Patients not recorded as malnourished had a median BMI that was around the 38 th percentile $(z$-score -0.62$)$. The Shwachman - Kulczycki score analysis at diagnosis demonstrated that almost half of the patients $(44.7 \%, n=21)$ had scores of 'excellent', followed by 'good', 'mild' and 'moderate' scores in $27.66 \%(n=13), 25.5 \%(n=12)$ and $2.1 \%(n=1)$ respectively. Furthermore, no "severe scores" were reported. Asthma was present in $25.5 \%(n=12)$ of cases, followed by CF-related diabetes in $8.5 \%(n=4)$, meanwhile allergic bronchopulmonary aspergillosis was reported in $6.4 \%(n=3)$.

Throughout the study period, a total of $14.9 \%(n=7)$ patients had exacerbations that required hospital management with clinicians, with an average of 2.5 hospitalizations per patient and an average inpatient stay of 18 days. Finally, during this study period, there were no deaths reported among the patients.

\section{Pulmonary function}

Pulmonary function tests were indicated in 28 patients (59.6\%). At diagnosis, spirometry showed values of $\mathrm{FEV}_{1}$ with a mean of $92.67 \%$ pred. $(S D= \pm 16.95)$, FVC with a mean of $100.81 \%$ pred. $(\mathrm{SD}= \pm 15.37)$ and $\mathrm{FEV}_{1} / \mathrm{FVC}$ with a mean of $89.81(\mathrm{SD}= \pm 7.69)$. When comparing the difference between $\mathrm{FEV}_{1}$ pulmonary function at diagnosis (baseline) and at follow-up, values show at three months follow-up a non-significant drop in $\mathrm{FEV}_{1}$ (Mean $=88.87 \pm 22.33 ; p>0.05)$ as well as at six months follow-up (Mean $=89.04 \pm 27.66 ; p>0.05)$ and a significant drop at nine months (Mean $=86.40 \pm 24.80 ; p<$ $0.05)$. In addition, follow-up mean difference comparison of FVC at three months follow-up was a non-significant drop $($ Mean $=98.65 \pm 18.75 ; p>0.05)$ and at six months 
Table 1 Clinical findings reported among patients with CF in Ecuador

\begin{tabular}{|c|c|c|c|c|}
\hline \multicolumn{5}{|l|}{ Clinical findings reported at CF Diagnosis } \\
\hline & $<5(\%)$ & 6 to $10(\%)$ & 11 to $15(\%)$ & $\geq 16(\%)$ \\
\hline Number of individuals ( $n$ ) & 13 & 11 & 15 & 8 \\
\hline Familiar history with asymptomatic patient & 15.4 & 9.1 & 6.7 & 0.0 \\
\hline \multicolumn{5}{|l|}{ Symptoms } \\
\hline Persistent respiratory symptoms & 69.2 & 90.9 & 93.3 & 100.0 \\
\hline Persistent gastrointestinal symptoms & 38.5 & 0.0 & 6.7 & 0.0 \\
\hline \multicolumn{5}{|l|}{ Signs } \\
\hline Digital clubbing & 0.0 & 27.3 & 13.3 & 25.0 \\
\hline Abnormal liver function test & 7.7 & 0.0 & 0.0 & 0.0 \\
\hline Sinus disease & 0.0 & 9.1 & 6.7 & 25.0 \\
\hline Malnutrition & 23.1 & 18.2 & 33.3 & 25.0 \\
\hline Body mass index percentile (average) & ${ }^{\mathrm{a}} 44.8$ & $a_{37.6}$ & ${ }^{\mathrm{a}} 37.8$ & ${ }^{\mathrm{a}} 28.3$ \\
\hline \multicolumn{5}{|l|}{ Score Shwachman - Kulczycki } \\
\hline Excellent & 53.9 & 63.6 & 33.3 & 25.0 \\
\hline Good & 46.1 & 27.3 & 20.0 & 12.5 \\
\hline Mild & 0.0 & 9.1 & 46.7 & 50.0 \\
\hline Moderate & 0.0 & 0.0 & 0.0 & 12.5 \\
\hline Severe & 0.0 & 0.0 & 0.0 & 0.0 \\
\hline \multicolumn{5}{|l|}{ Comorbidities } \\
\hline Cyrstic fibrosis related Diabetes & 0.0 & 0.0 & 6.7 & 37.5 \\
\hline Asthma & 0.0 & 36.4 & 40.0 & 25.0 \\
\hline Pulmonary Hypertension & 0.0 & 0.0 & 6.7 & 12.5 \\
\hline Celiac disease & 0.0 & 0.0 & 6.7 & 0.0 \\
\hline Cholelithiasis & 0.0 & 0.0 & 6.7 & 0.0 \\
\hline Allergic bronchopulmonary aspergillosis & 0.0 & 9.1 & 13.3 & 0.0 \\
\hline Pancreatitis & 0.0 & 18.2 & 0.0 & 0.0 \\
\hline Meconium ileus/other intestinal obstruction & 0.0 & 9.1 & 6.7 & 0.0 \\
\hline
\end{tabular}

${ }^{a}$ Values expressed in average

(Mean $=97.04 \pm 22.91 ; p>0.05)$, with a significant drop in FVC at nine months (Mean $=95.77 \pm 18.94 ; p<0.05$ )

(Fig. 1).

The differences in pulmonary function by age group and follow-up visit are displayed in Table 2.

The comparison among different times relative to the mean differences in $\mathrm{FEV}_{1} / \mathrm{FVC}$ at three (Mean $=87.86 \pm$ 9.36; $p>0.05)$, six (Mean $=87.89 \pm 11.63 ; p>0.05)$ and nine months $($ Mean $=85.55 \pm 13.26 ; p<0.05)$ is displayed in Table 2.

\section{Microbiology}

Bacteriological cultures and antibiograms were obtained every three months after the date of diagnosis. The most common isolated organism was Staphylococcus aureus (oxacillin sensitive) in $25.9 \%$ of the samples, followed by Haemophilus influenzae in $17.7 \%$ and Pseudomonas aeruginosa in $12.5 \%$. Age group analysis showed
Haemophilus influenza as the most common pathogen in patients younger than 10 years, while Moraxella Catarrhalis decreased in frequency in patients older than 10 years. Staphylococcus aureus (oxacillin sensitive and resistant) and Pseudomonas aeruginosa became more common in patients older than 10 years (Fig. 2).

A total of 120 susceptibility tests were performed; four species of gram-positive bacteria (S. aureus, CoagulaseNegative Staphylococcus, Streptococcus pneumoniae and $M$. catarrhalis) were the most common, with $S$. aureus showing the largest frequency $(n=95)$ among cultures, being most of them highly susceptible to sulfas, vancomycin, linezolid and ciprofloxacin while erythromycin was not effective (resistant) in most cases. Other cultures reported several types of gram-negative organisms, while only $10 \%$ of the isolate's cultures reported gram-positive organisms (Table 3). The less common pathogens found among cultures were Acinetobacter spp, Achromobacter 


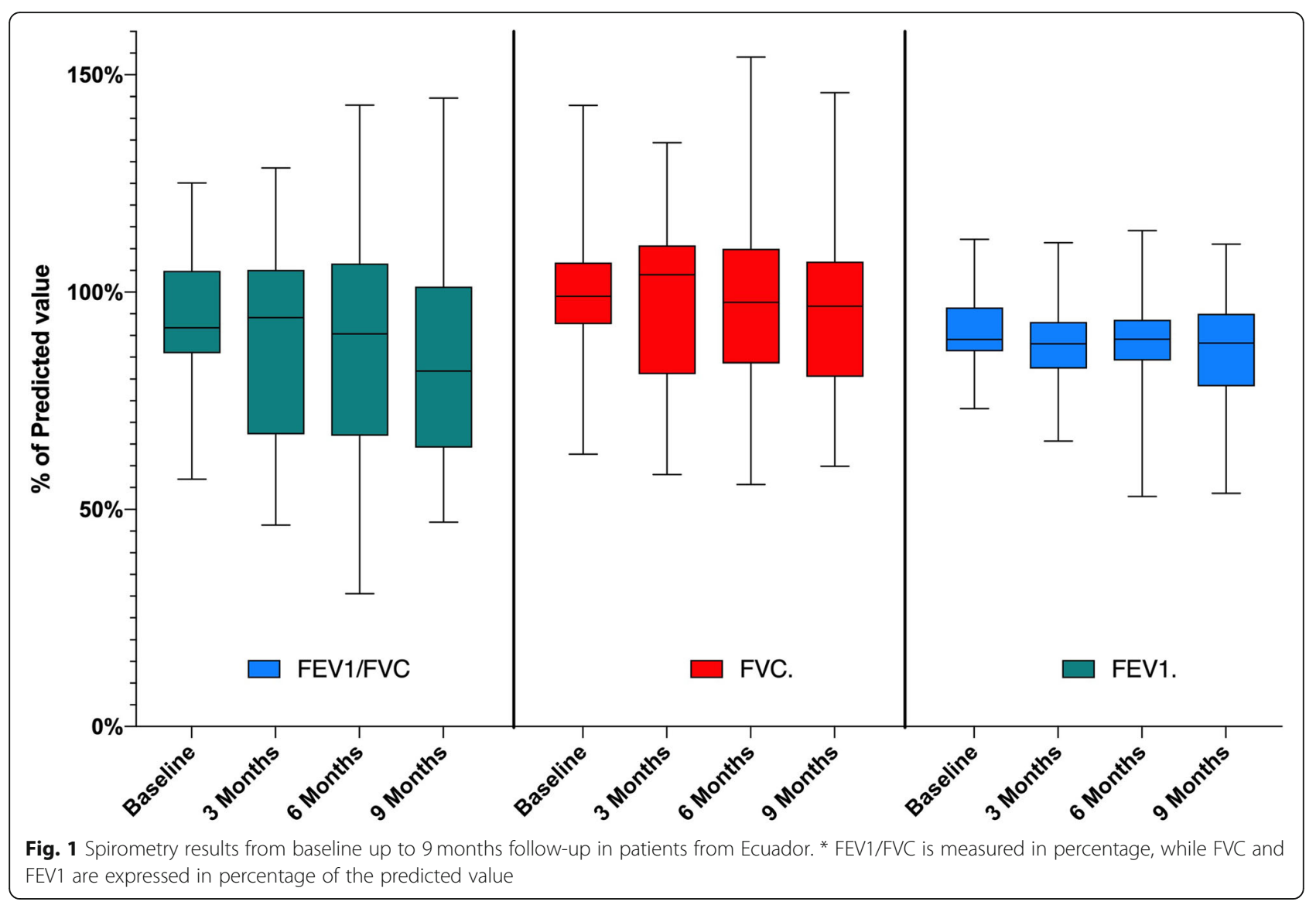

spp, Serratia spp and Raultella planticola. These microorganisms were found only once; therefore, susceptibility tests were not performed. The most frequent gramnegative pathogen was Pseudomonas spp, found in $29.2 \%$ of cultures. Pseudomonas spp were susceptible to Cefepime, Ceftazidime, Meropenem, Imipenem and
Piperacillin/Tazobactam, but showed resistance in almost $20 \%$ of cases against Amikacin and Gentamicin, as well as Ciprofloxacin in less than $10 \%$ of isolated cultures. Haemophilus spp was found in $16.7 \%$ of tests, with the bacteria demonstrating high sensitivity to Ampicillin/ Sulbactam, Azithromycin, Ceftriaxone and Cefuroxime,

Table 2 Pulmonary function among Ecuadorian patients with CF divided in three age groups

\begin{tabular}{|c|c|c|c|c|}
\hline Age group & Follow-up & ${ }^{*}$ FEV1\%pred. (SD) & ${ }^{*} F V C$ \%pred. (SD) & FEV1/FVC (SD) \\
\hline \multirow[t]{4}{*}{5 to 9 years $(n=11)$} & At diagnosis & $105.3(13.1)$ & $106,3(15.9)$ & $98,5(8.2)$ \\
\hline & 3-month & $95,8(27.2)$ & $100,8(22.3)$ & $92,5(10.9)$ \\
\hline & 6-month & $104,7(30.7)$ & $109,4(25.3)$ & $93,7(11.9)$ \\
\hline & 9-month & $105,3(29.5)$ & $107,0(23.5)$ & $95,3(10.9)$ \\
\hline \multirow[t]{4}{*}{10 to 14 years $(n=15)$} & At diagnosis & $87,7(12.8)$ & $97,5(11.5)$ & $87,9(4.3)$ \\
\hline & 3-month & $87,1(20.9)$ & $97,0(18.5)$ & $88,0(6.6)$ \\
\hline & 6-month & $86,6(22.7)$ & $94,1(20.1)$ & $88,0(8.3)$ \\
\hline & 9-month & $80,4(18.3)$ & $92,3(16.3)$ & $81,7(11.9)$ \\
\hline \multirow[t]{4}{*}{$\geq 15$ years $(n=8)$} & At diagnosis & $90,4(19.9)$ & $99,6(18.3)$ & $87,6(8.0)$ \\
\hline & 3-month & $85,8(22.3)$ & $100,0(18.2)$ & $83,0(11.6)$ \\
\hline & 6-month & 76,9 (31.9) & $90,1(25.3)$ & $72,8(29.4)$ \\
\hline & 9-month & $79,3(25.8)$ & $91,3(17.2)$ & $83,8(15.1)$ \\
\hline
\end{tabular}

*FEV1 (Forced expiratory ventilation at first second) and FVC (Forced vital capacity) are expressed as a percentage of the predicted values (\% pred.), while FEV1/ FVC is expressed in percentage 


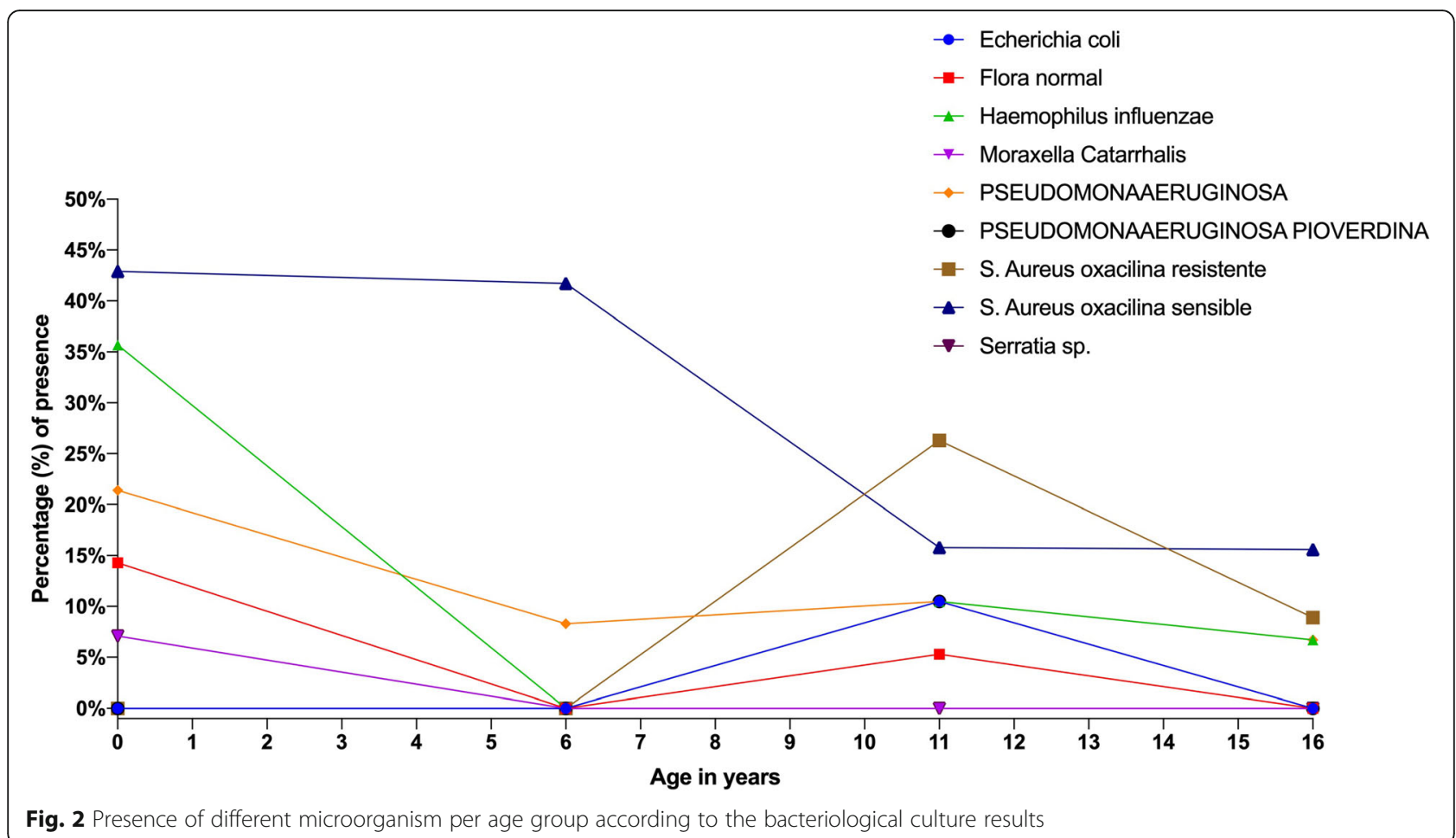

however, was resistant to Co-trimoxazole and Ampicillin in less than 50 and $15 \%$ of tests respectively. Enterobacter spp was isolated in $10.8 \%$ of the samples and showed to be highly sensitive to Ceftazidime and Gentamicin as well as to Ceftriaxone and Piperacillin/Tazobactam (Table 3).

\section{Genetic analysis}

The genetic tests were comprehensively compared and correlated with the information available from the ClinVar and the Single Nucleotide Polymorphism (dbSNP) databases (Table 4). Among children attending HCAM, 36 out of 47 patients underwent CFTR sequence analysis. A total of 23 patients had a specifically targeted variant panel, and 13 of them had full-length gene sequencing.

The most common pathogenic variant reported was F508del, found in $52.8 \%(n=19)$ of tested patients. The variant was found in homozygous state in four patients and in heterozygous state in 15 patients. The second most common variant reported was H609R, found in 13 patients (36.1\%), most of them in heterozygous state $(n=11)$, while homozygous state was only found among indigenous patients, and may be related to a founder effect [28]. The third most common pathogenic variants were G85E and N1303K, both found in $11.1 \%$ of the patients. Less common variants included the W1098X, G542X and the R170H (Table 5).

We found some variants that had already been reported in previous reports and also some not previously reported, including g.204099A $>\mathrm{C}$ in $19.4 \% \quad(n=7)$, followed by M470V in $16.7 \%(n=6), c .869+11 \mathrm{C}>\mathrm{T}$ in $11.1 \%(n=4)$ and the g.206359C $>\mathrm{A}$ in $11.1 \%(n=4)$ of cases. Finally, the less commonly reported variants were the g.19395G > A, c. $164+12 \mathrm{~T}>\mathrm{C}, \mathrm{Q} 1463^{*}$ and other particular variants as shown in Table 5 .

\section{Ecuadorian genetic profile}

Seven patients who were compound heterozygous for different variants also had other multiple allelic combinations never seen before, such as the g.204099A > C polymorphism, in the seven of them in homozygous state. This polymorphism g.204099A > C has only been reported in Ecuadorian populations to date, establishing its role as a predisposing genetic factor in positive cases (Table 6).

\section{Discussion}

$\mathrm{CF}$ is an autosomal recessive disorder seen worldwide, with typically a higher prevalence in Caucasian populations [11]. A significant problem in developing countries is that CF patients have a shorter life expectancy, with many patients diagnosed at a later stage in life once symptoms of the disease have manifested [29]. This study has shown that the average age of diagnosis is after the age of nine, with only $38.3 \%$ of patients diagnosed before five years of age. Later stage diagnosis is common among developing countries, while in high-income 
Table 3 Bacteriological culture results from Ecuadorian patients with CF

\begin{tabular}{|c|c|c|c|c|c|c|c|c|c|}
\hline & Microorganisms & $\begin{array}{l}\text { Isolations } \\
\text { (n) }\end{array}$ & Antibiotics & $\begin{array}{l}\text { Susceptibility } \\
\text { (n) }\end{array}$ & $\begin{array}{l}\text { Susceptibility } \\
(\%)\end{array}$ & $\begin{array}{l}\text { Resistance } \\
\text { (n) }\end{array}$ & $\begin{array}{l}\text { Resistance } \\
(\%)\end{array}$ & $\begin{array}{l}\text { Non- } \\
\text { described } \\
\text { (n) }\end{array}$ & $\begin{array}{l}\text { Non- } \\
\text { described } \\
(\%)\end{array}$ \\
\hline \multirow{22}{*}{$\begin{array}{l}\text { Gram- } \\
\text { positive }\end{array}$} & \multirow[t]{8}{*}{ Staphylococcus aureus } & \multirow[t]{8}{*}{95} & Ciprofloxacin & 55 & 57.89 & 4 & 4.21 & 36 & 37.89 \\
\hline & & & Clindamycin & 46 & 48.42 & 38 & 40.00 & 11 & 11.58 \\
\hline & & & Erythromycin & 19 & 20.00 & 61 & 64.21 & 15 & 15.79 \\
\hline & & & Gentamicin & 64 & 67.37 & 15 & 15.79 & 16 & 16.84 \\
\hline & & & Linezolid & 55 & 57.89 & 0 & 0.00 & 40 & 42.11 \\
\hline & & & Oxacillin & 40 & 42.11 & 39 & 41.05 & 16 & 16.84 \\
\hline & & & Co-trimoxazole & 74 & 77.89 & 1 & 1.05 & 20 & 21.05 \\
\hline & & & Vancomycin & 51 & 53.68 & 0 & 0.00 & 44 & 46.32 \\
\hline & \multirow{7}{*}{$\begin{array}{l}\text { Coagulase-Negative } \\
\text { Staphylococcus }\end{array}$} & \multirow[t]{7}{*}{3} & Clindamycin & 0 & 0.00 & 2 & 66.67 & 1 & 33.33 \\
\hline & & & Gentamicin & 2 & 66.67 & 0 & 0.00 & 1 & 33.33 \\
\hline & & & Erythromycin & 0 & 0.00 & 2 & 66.67 & 1 & 33.33 \\
\hline & & & Oxacillin & 1 & 33.33 & 1 & 33.33 & 1 & 33.33 \\
\hline & & & Penicillin & 0 & 0.00 & 2 & 66.67 & 1 & 33.33 \\
\hline & & & Co-trimoxazole & 2 & 66.67 & 0 & 0.00 & 1 & 33.33 \\
\hline & & & Vancomycin & 2 & 66.67 & 0 & 0.00 & 1 & 33.33 \\
\hline & \multirow{4}{*}{$\begin{array}{l}\text { Streptococcus } \\
\text { pneumoniae }\end{array}$} & \multirow[t]{4}{*}{7} & Ceftriaxone & 4 & 57.14 & 0 & 0.00 & 3 & 42.86 \\
\hline & & & Clindamycin & 2 & 28.57 & 1 & 14.29 & 4 & 57.14 \\
\hline & & & Penicillin & 4 & 57.14 & 2 & 28.57 & 1 & 14.29 \\
\hline & & & Co-trimoxazole & 2 & 28.57 & 3 & 42.86 & 2 & 28.57 \\
\hline & \multirow[t]{2}{*}{ Corynebacterium spp } & \multirow[t]{2}{*}{2} & Doxycycline & 1 & 50.00 & 0 & 0.00 & 1 & 50.00 \\
\hline & & & Levofloxacin & 1 & 50.00 & 0 & 0.00 & 1 & 50.00 \\
\hline & \multirow[t]{8}{*}{ Escherichia coli } & \multirow[t]{8}{*}{11} & Amikacin & 6 & 54.55 & 3 & 27.27 & 2 & 18.18 \\
\hline \multirow[t]{18}{*}{$\begin{array}{l}\text { Gram } \\
\text { negatives }\end{array}$} & & & $\begin{array}{l}\text { Ampicillin/ } \\
\text { sulbactam }\end{array}$ & 0 & 0.00 & 8 & 72.73 & 3 & 27.27 \\
\hline & & & Cefepime & 1 & 9.09 & 9 & 81.82 & 1 & 9.09 \\
\hline & & & Ceftazidime & 1 & 9.09 & 9 & 81.82 & 1 & 9.09 \\
\hline & & & Ciprofloxacin & 1 & 9.09 & 7 & 63.64 & 3 & 27.27 \\
\hline & & & Gentamicin & 4 & 36.36 & 4 & 36.36 & 3 & 27.27 \\
\hline & & & Imipenem & 10 & 90.91 & 0 & 0.00 & 1 & 9.09 \\
\hline & & & $\begin{array}{l}\text { Piperacillin/ } \\
\text { tazobactam }\end{array}$ & 4 & 36.36 & 3 & 27.27 & 4 & 36.36 \\
\hline & \multirow[t]{4}{*}{ Enterobacter spp } & \multirow[t]{4}{*}{13} & Ceftazidime & 10 & 76.92 & 0 & 0.00 & 3 & 23.08 \\
\hline & & & Ceftriaxone & 8 & 61.54 & 0 & 0.00 & 5 & 38.46 \\
\hline & & & Gentamicin & 10 & 76.92 & 0 & 0.00 & 3 & 23.08 \\
\hline & & & $\begin{array}{l}\text { Piperacillin/ } \\
\text { tazobactam }\end{array}$ & 8 & 61.54 & 0 & 0.00 & 5 & 38.46 \\
\hline & \multirow[t]{6}{*}{ Haemophilus spp } & \multirow[t]{6}{*}{20} & Ampicillin & 13 & 65.00 & 3 & 15.00 & 4 & 20.00 \\
\hline & & & $\begin{array}{l}\text { Ampicillin/ } \\
\text { sulbactam }\end{array}$ & 14 & 70.00 & 1 & 5.00 & 5 & 25.00 \\
\hline & & & Azithromycin & 15 & 75.00 & 0 & 0.00 & 5 & 25.00 \\
\hline & & & Ceftriaxone & 13 & 65.00 & 0 & 0.00 & 7 & 35.00 \\
\hline & & & Cefuroxime & 13 & 65.00 & 1 & 5.00 & 6 & 30.00 \\
\hline & & & Co-trimoxazole & 6 & 30.00 & 9 & 45.00 & 5 & 25.00 \\
\hline & Klebsiella spp & 5 & Amikacin & 3 & 60.00 & 0 & 0.00 & 2 & 40.00 \\
\hline
\end{tabular}


Table 3 Bacteriological culture results from Ecuadorian patients with CF (Continued)

\begin{tabular}{|c|c|c|c|c|c|c|c|c|}
\hline Microorganisms & $\begin{array}{l}\text { Isolations } \\
\text { (n) }\end{array}$ & Antibiotics & $\begin{array}{l}\text { Susceptibility } \\
\text { (n) }\end{array}$ & $\begin{array}{l}\text { Susceptibility } \\
(\%)\end{array}$ & $\begin{array}{l}\text { Resistance } \\
\text { (n) }\end{array}$ & $\begin{array}{l}\text { Resistance } \\
(\%)\end{array}$ & $\begin{array}{l}\text { Non- } \\
\text { described } \\
\text { (n) }\end{array}$ & $\begin{array}{l}\text { Non- } \\
\text { described } \\
(\%)\end{array}$ \\
\hline & & $\begin{array}{l}\text { Ampicillin/ } \\
\text { sulbactam }\end{array}$ & 3 & 60.00 & 0 & 0.00 & 2 & 40.00 \\
\hline & & Cefepime & 3 & 60.00 & 0 & 0.00 & 2 & 40.00 \\
\hline & & Ceftazidime & 4 & 80.00 & 0 & 0.00 & 1 & 20.00 \\
\hline & & Ciprofloxacin & 3 & 60.00 & 0 & 0.00 & 2 & 40.00 \\
\hline & & Imipenem & 3 & 60.00 & 0 & 0.00 & 2 & 40.00 \\
\hline \multirow[t]{5}{*}{ Moraxella spp } & 7 & $\begin{array}{l}\text { Amoxicillin/ } \\
\text { clavulanate }\end{array}$ & 4 & 57.14 & 0 & 0.00 & 3 & 42.86 \\
\hline & & Ampicillin & 0 & 0.00 & 5 & 71.43 & 2 & 28.57 \\
\hline & & $\begin{array}{l}\text { Ampicillin/ } \\
\text { sulbactam }\end{array}$ & 5 & 71.43 & 1 & 14.29 & 1 & 14.29 \\
\hline & & Azithromycin & 6 & 85.71 & 0 & 0.00 & 1 & 14.29 \\
\hline & & Cefuroxime & 6 & 85.71 & 0 & 0.00 & 1 & 14.29 \\
\hline \multirow[t]{8}{*}{ Pseudomonas spp } & 35 & Amikacin & 11 & 31.43 & 6 & 17.14 & 18 & 51.43 \\
\hline & & Cefepime & 27 & 77.14 & 3 & 8.57 & 5 & 14.29 \\
\hline & & Ceftazidime & 31 & 88.57 & 1 & 2.86 & 3 & 8.57 \\
\hline & & Ciprofloxacin & 21 & 60.00 & 4 & 11.43 & 10 & 28.57 \\
\hline & & Gentamicin & 16 & 45.71 & 8 & 22.86 & 11 & 31.43 \\
\hline & & Imipenem & 20 & 57.14 & 1 & 2.86 & 14 & 40.00 \\
\hline & & Meropenem & 26 & 74.29 & 1 & 2.86 & 8 & 22.86 \\
\hline & & $\begin{array}{l}\text { Piperacillin/ } \\
\text { tazobactam }\end{array}$ & 25 & 71.43 & 2 & 5.71 & 8 & 22.86 \\
\hline
\end{tabular}

countries, more than $95 \%$ of the patients are diagnosed during the first year of life $[11,30]$.

In the sample of patients, respiratory symptoms (cough, recurrent pneumonia, dyspnea on exertion and chest pain) were most commonly described, followed by gastrointestinal symptoms including abdominal distention, increased frequency of stools, flatulence and steatorrhea. The clinical presentation in Ecuadorian patients appears to be similar to those reports from other LatinAmerican countries [23, 31]. As often reported, BMI values are often low, and malnutrition has manifested. In our analysis, we found that the patients had an average BMI of $16.6 \mathrm{~kg} / \mathrm{m}^{2}$, with girls showing greater average BMI values $\left(17.4 \mathrm{~kg} / \mathrm{m}^{2}\right)$ compared to the boys $(15.8$ $\mathrm{kg} / \mathrm{m}^{2}$ ). Culhane et al. reported higher BMI values for girls being slightly lower $\left(21 \mathrm{~kg} / \mathrm{m}^{2}\right)$ than boys $(22 \mathrm{~kg} /$ $\mathrm{m}^{2}$ ), probably due to increased energy losses, increased energy needs or differences in inadequate calorie intake among boys [32]. Despite the later diagnosis of the disease, malnutrition was presented in only a quarter of our patients. The Shwachman-Kulczycki scores of 'good' or 'excellent' were seen in more than $70 \%$ of patients. This grading system is often used to track progress in these types of patients $[33,34]$.
In terms of comorbidities, a diagnosis of asthma in $\mathrm{CF}$ patients is difficult due to overlapping respiratory symptoms presenting in patients. Around $20-30 \%$ of the patients with CF can have a concomitant clinical diagnosis of Asthma in population studies [35, 36]. Our results show that $33 \%$ of our patients had this comorbidity, which is compatible with previous works.

The $\mathrm{FEV}_{1}, \mathrm{FVC}$ and the Tiffeneau-Pinelli index were within the normal range in the majority of patients. Mild lower airway obstruction was seen in all age groups, which is an interesting finding since lung function would have been expected to be lower in patients with a delayed CF diagnosis, as reported elsewhere [34]. Lung function during follow-up at nine months post-diagnosis was shown to be preserved, which was likely related to the quality of management, which includes correct antibiotic management and appropriate clinical follow-up schemes [28].

Preventing complications is essential for this type of disease management. Periodical cultures had proven to be an important clinical step to take when looking to prevent further complications and implement early treatment when needed. In our report, the most common microorganism reported was Staphylococcus 
Table 4 Classification of the genetic variants found among Ecuadorian children with CF

\begin{tabular}{|c|c|c|c|c|c|c|c|c|}
\hline $\begin{array}{l}\text { Genetic } \\
\text { identification }\end{array}$ & $\begin{array}{l}\text { Nucleotide } \\
\text { identification }\end{array}$ & $\begin{array}{l}\text { Protein identification } \\
\text { (change) }\end{array}$ & dbSNP ID & $\begin{array}{l}\text { Clinical } \\
\text { Significance }\end{array}$ & $\begin{array}{l}\text { Molecular } \\
\text { consequence }\end{array}$ & $\begin{array}{l}\text { Class of } \\
\text { allele } \\
\text { mutation }\end{array}$ & $\begin{array}{l}\text { Clinical } \\
\text { classification }\end{array}$ & $\begin{array}{l}\text { CFTR } 2 \text { database } \\
\text { patient reports }\end{array}$ \\
\hline g.19395G > A & - & - & $\begin{array}{l}\text { Not } \\
\text { reported }\end{array}$ & $\begin{array}{l}\text { Not } \\
\text { reported }\end{array}$ & Not reported & $\begin{array}{l}\text { Non } \\
\text { classified }\end{array}$ & $\begin{array}{l}\text { Non } \\
\text { classified }\end{array}$ & Not reported \\
\hline g.43555G > C & - & - & $\begin{array}{l}\text { Not } \\
\text { reported }\end{array}$ & $\begin{array}{l}\text { Not } \\
\text { reported }\end{array}$ & Not reported & $\begin{array}{l}\text { Non } \\
\text { classified }\end{array}$ & $\begin{array}{l}\text { Non } \\
\text { classified }\end{array}$ & Not reported \\
\hline g.43575G > C & - & - & $\begin{array}{l}\text { Not } \\
\text { reported }\end{array}$ & $\begin{array}{l}\text { Not } \\
\text { reported }\end{array}$ & Not reported & $\begin{array}{l}\text { Non } \\
\text { classified }\end{array}$ & $\begin{array}{l}\text { Non } \\
\text { classified }\end{array}$ & Not reported \\
\hline g.43580G > T & - & - & $\begin{array}{l}\text { Not } \\
\text { reported }\end{array}$ & $\begin{array}{l}\text { Not } \\
\text { reported }\end{array}$ & Not reported & $\begin{array}{l}\text { Non } \\
\text { Classified }\end{array}$ & $\begin{array}{l}\text { Non } \\
\text { Classified }\end{array}$ & Not reported \\
\hline g.43583A > G & - & - & $\begin{array}{l}\text { Not } \\
\text { reported }\end{array}$ & $\begin{array}{l}\text { Not } \\
\text { reported }\end{array}$ & Not reported & $\begin{array}{l}\text { Non } \\
\text { classified }\end{array}$ & $\begin{array}{l}\text { Non } \\
\text { classified }\end{array}$ & Not reported \\
\hline g.43592 T > C & $\begin{array}{l}\mathrm{C} .164+12 \\
\mathrm{~T}>\mathrm{C}\end{array}$ & - & rs121908790 & Uncertain & Intron variant & $\begin{array}{l}\text { Non } \\
\text { classified }\end{array}$ & $\begin{array}{l}\text { Non } \\
\text { classified }\end{array}$ & Not reported \\
\hline g.43594A > G & - & - & $\begin{array}{l}\text { Not } \\
\text { reported }\end{array}$ & $\begin{array}{l}\text { Not } \\
\text { reported }\end{array}$ & Not reported & $\begin{array}{l}\text { Non } \\
\text { Classified }\end{array}$ & $\begin{array}{l}\text { Non } \\
\text { classified }\end{array}$ & Not reported \\
\hline g.48340G > A & c. $254 \mathrm{G}>\mathrm{A}$ & p.Gly85Glu (G85E) & rs75961395 & Pathogenic & $\begin{array}{l}\text { Missense } \\
\text { variant }\end{array}$ & Class II & A group & 584 \\
\hline g.73512G > A & c.509G > A & p.Arg170His (R170H) & rs1800079 & Pathogenic & $\begin{array}{l}\text { Missense } \\
\text { variant }\end{array}$ & $\begin{array}{l}\text { Non } \\
\text { classified }\end{array}$ & $\begin{array}{l}\text { Non } \\
\text { classified }\end{array}$ & 11 \\
\hline g.70332G > T & $\begin{array}{l}\mathrm{c} .489+1 \mathrm{G}> \\
\mathrm{T}\end{array}$ & $621+1 G>T$ & rs78756941 & Pathogenic & $\begin{array}{l}\text { Splice donor } \\
\text { variant }\end{array}$ & Class I & A group & 1293 \\
\hline g.74534G >C & c. $1624 \mathrm{G}>\mathrm{T}$ & p.Gly542Ter (G542X) & rs113993959 & Pathogenic & $\begin{array}{l}\text { Nonsense } \\
\text { variant }\end{array}$ & Class I & A group & 3489 \\
\hline g.206154C > T & $\begin{array}{l}\mathrm{c} .869+ \\
11 \mathrm{C}>\mathrm{T}\end{array}$ & - & rs1800503 & Benign & Intron variant & $\begin{array}{l}\text { Non } \\
\text { classified }\end{array}$ & $\begin{array}{l}\text { Non } \\
\text { classified }\end{array}$ & Not reported \\
\hline g.79435G > T & $c .988 \mathrm{G}>\mathrm{T}$ & p.Gly330Ter (G330*) & rs79031340 & Pathogenic & $\begin{array}{l}\text { Nonsense } \\
\text { variant }\end{array}$ & $\begin{array}{l}\text { Non } \\
\text { classified }\end{array}$ & $\begin{array}{l}\text { Non } \\
\text { classified }\end{array}$ & 23 \\
\hline g.98696A > G & c. $1408=$ & p.Val470 = (M470V) & rs213950 & Benign & $\begin{array}{l}\text { Missense } \\
\text { variant }\end{array}$ & $\begin{array}{l}\text { Non } \\
\text { classified }\end{array}$ & C group & 209 \\
\hline $\begin{array}{l}\text { g.98808 } \\
\text { 98811delTCT }\end{array}$ & $\begin{array}{l}\text { c.1521 } \\
1523 \mathrm{del}\end{array}$ & $\begin{array}{l}\text { p.Phe508del } \\
\text { (F508del) }\end{array}$ & rs113993960 & Pathogenic & $\begin{array}{l}\text { Inframe } \\
\text { variant }\end{array}$ & Class ॥ & A group & 65,046 \\
\hline g.131210A > G & c. $1826 A>G$ & p.His609Arg (H609R) & rs397508310 & Pathogenic & $\begin{array}{l}\text { Missense } \\
\text { variant }\end{array}$ & $\begin{array}{l}\text { Non } \\
\text { classified }\end{array}$ & $\begin{array}{l}\text { Non } \\
\text { classified }\end{array}$ & 9 \\
\hline $\begin{array}{l}\text { g.117592218_ } \\
\text { 117592219dup }\end{array}$ & c.2052dupA & $\begin{array}{l}\text { p.Gln685fs } \\
\text { (Gln685Thrfs) }\end{array}$ & rs121908746 & Pathogenic & $\begin{array}{l}\text { frameshift } \\
\text { variant }\end{array}$ & $\begin{array}{l}\text { Non } \\
\text { classified }\end{array}$ & $\begin{array}{l}\text { Non } \\
\text { classified }\end{array}$ & 324 \\
\hline g.117592382del & c.2215del & $\begin{array}{l}\text { p.Val739fs } \\
\text { (2347delG) }\end{array}$ & rs397508353 & Pathogenic & $\begin{array}{l}\text { Frameshift } \\
\text { variant }\end{array}$ & $\begin{array}{l}\text { Non } \\
\text { classified }\end{array}$ & $\begin{array}{l}\text { Non } \\
\text { classified }\end{array}$ & 38 \\
\hline g.134218 T > G & c. $2562 \mathrm{~T}>\mathrm{G}$ & p.Thr854 = (T854T) & rs1042077 & Benign & $\begin{array}{l}\text { Synonymous } \\
\text { variant }\end{array}$ & $\begin{array}{l}\text { Non } \\
\text { classified }\end{array}$ & $\begin{array}{l}\text { Non } \\
\text { classified }\end{array}$ & 36 \\
\hline g.142999 G > A & c. $2908 \mathrm{G}>\mathrm{A}$ & p.Gly970Ser (G970S) & rs397508453 & Uncertain & $\begin{array}{l}\text { Missense } \\
\text { variant }\end{array}$ & $\begin{array}{l}\text { Non } \\
\text { classified }\end{array}$ & $\begin{array}{l}\text { Non } \\
\text { classified }\end{array}$ & 10 \\
\hline g.143018G > T & - & - & $\begin{array}{l}\text { Not } \\
\text { reported }\end{array}$ & $\begin{array}{l}\text { Not } \\
\text { reported }\end{array}$ & Not reported & $\begin{array}{l}\text { Non } \\
\text { classified }\end{array}$ & $\begin{array}{l}\text { Non } \\
\text { classified }\end{array}$ & Not reported \\
\hline g.149918 T > A & - & - & $\begin{array}{l}\text { Not } \\
\text { reported }\end{array}$ & $\begin{array}{l}\text { Not } \\
\text { reported }\end{array}$ & Not reported & $\begin{array}{l}\text { Non } \\
\text { classified }\end{array}$ & $\begin{array}{l}\text { Non } \\
\text { classified }\end{array}$ & Not reported \\
\hline g.74629 T > C & c. $3294 G>A$ & $\begin{array}{l}\text { p.Trp1098Ter } \\
\text { (W1098X) }\end{array}$ & rs397508533 & Pathogenic & $\begin{array}{l}\text { Nonsense } \\
\text { variant }\end{array}$ & $\begin{array}{l}\text { Non } \\
\text { classified }\end{array}$ & $\begin{array}{l}\text { Non } \\
\text { classified }\end{array}$ & 9 \\
\hline g. $181807 A>G$ & c. $3870 A>G$ & p.Pro1290 $=(P 1290 P)$ & rs1800130 & Benign & $\begin{array}{l}\text { Synonymous } \\
\text { variant }\end{array}$ & $\begin{array}{l}\text { Non } \\
\text { classified }\end{array}$ & $\begin{array}{l}\text { Non } \\
\text { classified }\end{array}$ & Not reported \\
\hline g.192094C > G & c. $3909 C>G$ & $\begin{array}{l}\text { p.Asn1303Lys } \\
\text { (N1303K) }\end{array}$ & rs80034486 & Pathogenic & $\begin{array}{l}\text { Missense } \\
\text { variant }\end{array}$ & Class II & A group & 2147 \\
\hline g.204099A > C & - & - & $\begin{array}{l}\text { Not } \\
\text { reported }\end{array}$ & $\begin{array}{l}\text { Not } \\
\text { reported }\end{array}$ & Not reported & $\begin{array}{l}\text { Non } \\
\text { classified }\end{array}$ & $\begin{array}{l}\text { Non } \\
\text { classified }\end{array}$ & Not reported \\
\hline
\end{tabular}


Table 4 Classification of the genetic variants found among Ecuadorian children with CF (Continued)

\begin{tabular}{|c|c|c|c|c|c|c|c|c|}
\hline $\begin{array}{l}\text { Genetic } \\
\text { identification }\end{array}$ & $\begin{array}{l}\text { Nucleotide } \\
\text { identification }\end{array}$ & $\begin{array}{l}\text { Protein identification } \\
\text { (change) }\end{array}$ & dbSNP ID & $\begin{array}{l}\text { Clinical } \\
\text { Significance }\end{array}$ & $\begin{array}{l}\text { Molecular } \\
\text { consequence }\end{array}$ & $\begin{array}{l}\text { Class of } \\
\text { allele } \\
\text { mutation }\end{array}$ & $\begin{array}{l}\text { Clinical } \\
\text { classification }\end{array}$ & $\begin{array}{l}\text { CFTR } 2 \text { database } \\
\text { patient reports }\end{array}$ \\
\hline g.129569G > A & $\begin{array}{l}\text { C. } 1680-1 G> \\
\text { A }\end{array}$ & $1812-1 G>A$ & rs121908794 & Pathogenic & $\begin{array}{l}\text { Splice } \\
\text { acceptor } \\
\text { variant }\end{array}$ & $\begin{array}{l}\text { Non } \\
\text { classified }\end{array}$ & $\begin{array}{l}\text { Non } \\
\text { classified }\end{array}$ & 31 \\
\hline g.206271 G > A & c. $4387 \mathrm{C}>\mathrm{T}$ & $\begin{array}{l}\text { p.Gln1463Ter } \\
\text { (Q1463*) }\end{array}$ & rs886044425 & Uncertain & $\begin{array}{l}\text { Nonsense } \\
\text { variant }\end{array}$ & $\begin{array}{l}\text { Non } \\
\text { classified }\end{array}$ & $\begin{array}{l}\text { Non } \\
\text { classified }\end{array}$ & Not reported \\
\hline g. $206359 C>A$ & - & - & $\begin{array}{l}\text { Not } \\
\text { reported }\end{array}$ & $\begin{array}{l}\text { Not } \\
\text { reported }\end{array}$ & Not reported & $\begin{array}{l}\text { Non } \\
\text { classified }\end{array}$ & $\begin{array}{l}\text { Non } \\
\text { classified }\end{array}$ & Not reported \\
\hline
\end{tabular}

aureus, with varying antibiotic sensitivity profiles. The main differences were displayed in terms of age groups, showing a lower incidence of Moraxella catharralis and Haemophilus influenzae among cultures from patients over 10 years, while these patients had an increase in the number of positive cultures for S. aureus and Pseudomonas aeruginosa, an observation previously reported elsewhere [37]. The presence of $P$. aeruginosa within the respiratory tract is often used as a positive marker for severity among children and adults with CF [38, 39].

Table 5 Molecular findings among pediatric patients diagnosed with CF in a tertiary level hospital in Ecuador

\begin{tabular}{|c|c|c|c|c|c|}
\hline Genetic identification & Nucleotide identification & Protein identification (change) & Number of reports & Heterozygosis & Homozygosis \\
\hline g.19395G > A & - & - & 2 & - & 2 \\
\hline g. $43555 G>C$ & - & - & 1 & 1 & - \\
\hline g. $43575 G>C$ & - & - & 1 & 1 & - \\
\hline g.43580G > T & - & - & 1 & 1 & - \\
\hline g. $43583 A>G$ & - & - & 1 & 1 & - \\
\hline g.43592T >C & C. $164+12 T>C$ & - & 2 & 2 & - \\
\hline g.43594A > G & - & - & 1 & 1 & - \\
\hline g. $48340 \mathrm{G}>\mathrm{A}$ & $c .254 G>A$ & p.Gly85Glu (G85E) & 4 & 4 & - \\
\hline g.73512G > A & C. $509 \mathrm{G}>\mathrm{A}$ & p.Arg170His (R170H) & 1 & 1 & - \\
\hline g.70332G > T & $c .489+1 G>T$ & $621+1 G>T$ & 1 & 1 & - \\
\hline g.74534G >C & c. $1624 G>T$ & p.Gly542Ter (G542X) & 2 & 2 & - \\
\hline g.206154C > T & $c .869+11 C>T$ & - & 4 & 3 & 1 \\
\hline g.79435G > T & $c .988 \mathrm{G}>\mathrm{T}$ & p.Gly330Ter (G330*) & 1 & - & 1 \\
\hline g. $98696 \mathrm{~A}>\mathrm{G}$ & c. $1408=$ & p.Val470 = (M470V) & 6 & 3 & 3 \\
\hline g.98808_98811delTCT & c.1521_1523del & p.Phe508del (F508del) & 19 & 15 & 4 \\
\hline g.131210A > G & c. $1826 A>G$ & p.His609Arg (H609R) & 13 & 11 & 2 \\
\hline g.117592218_117592219dup & c.2052dupA & p.Gln685fs (Gln685Thrfs) & 1 & 1 & - \\
\hline g.117592382del & c.2215del & p.Val739fs (2347delG) & 1 & 1 & - \\
\hline g.134218T > G & c. $2562 \mathrm{~T}>\mathrm{G}$ & p.Thr854 = (T854T) & 1 & 1 & - \\
\hline g.142999 G > A & c. $2908 \mathrm{G}>\mathrm{A}$ & p.Gly970Ser (G970S) & 1 & 1 & - \\
\hline g.143018G > T & - & - & 1 & 1 & - \\
\hline g.149918T > A & - & - & 1 & 1 & - \\
\hline g.74629T >C & c. $3294 G>A$ & p.Trp1098Ter (W1098X) & 3 & 3 & - \\
\hline g.181807A > G & c. $3870 A>G$ & p.Pro1290 = (P1290P) & 1 & 1 & - \\
\hline g.192094C > G & c. $3909 C>G$ & p.Asn1303Lys (N1303K) & 4 & 4 & - \\
\hline g.204099A > C & - & - & 7 & - & 7 \\
\hline g.129569G > A & c. $1680-1 \mathrm{G}>\mathrm{A}$ & $1812-1 G>A$ & 1 & 1 & - \\
\hline g.206271 G > A & $c .4387 C>T$ & p.Gln1463Ter (Q1463*) & 2 & 2 & - \\
\hline g. 206359 C > A & - & - & 4 & - & 4 \\
\hline
\end{tabular}


Table 6 Predisposing genetic factors in CF positive cases in a cohort of Ecuadorian children attending the HECAM hospital

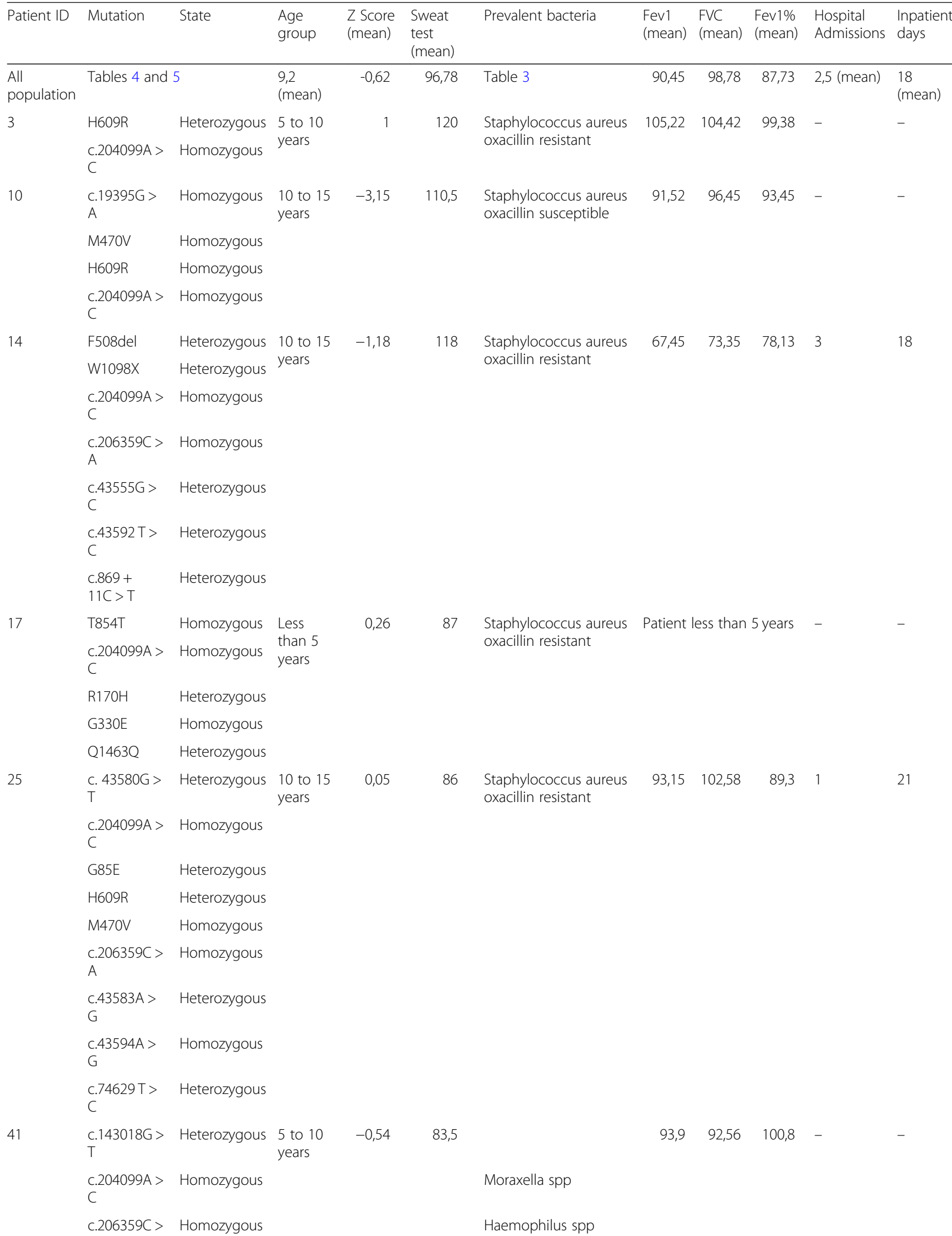


Table 6 Predisposing genetic factors in CF positive cases in a cohort of Ecuadorian children attending the HECAM hospital (Continued)

\begin{tabular}{|c|c|c|c|c|c|c|c|c|c|c|c|}
\hline Patient ID & Mutation & State & $\begin{array}{l}\text { Age } \\
\text { group }\end{array}$ & $\begin{array}{l}\text { Z Score } \\
\text { (mean) }\end{array}$ & $\begin{array}{l}\text { Sweat } \\
\text { test } \\
\text { (mean) }\end{array}$ & Prevalent bacteria & $\begin{array}{l}\text { Fev1 } \\
\text { (mean) }\end{array}$ & $\begin{array}{l}\mathrm{FVC} \\
\text { (mean) }\end{array}$ & $\begin{array}{l}\text { Fev1\% } \\
\text { (mean) }\end{array}$ & $\begin{array}{l}\text { Hospital } \\
\text { Admissions }\end{array}$ & $\begin{array}{l}\text { Inpatient } \\
\text { days }\end{array}$ \\
\hline & M470V & Homozygous & & & & & & & & & \\
\hline & G970S & Heterozygous & & & & & & & & & \\
\hline \multirow[t]{5}{*}{45} & $\begin{array}{l}\text { c. } 19395 G> \\
\text { A }\end{array}$ & Homozygous & \multirow[t]{5}{*}{$\begin{array}{l}10 \text { to } 15 \\
\text { years }\end{array}$} & \multirow[t]{5}{*}{$-2,16$} & \multirow[t]{5}{*}{67} & \multirow[t]{5}{*}{$\begin{array}{l}\text { Staphylococcus aureus } \\
\text { oxacillin susceptible }\end{array}$} & \multirow[t]{5}{*}{72,28} & \multirow[t]{5}{*}{88,58} & \multirow[t]{5}{*}{82,93} & \multirow[t]{5}{*}{-} & \multirow[t]{5}{*}{-} \\
\hline & $\begin{array}{l}\text { c. } 74534 G> \\
C\end{array}$ & Heterozygous & & & & & & & & & \\
\hline & P1290P & Heterozygous & & & & & & & & & \\
\hline & M470V & Heterozygous & & & & & & & & & \\
\hline & Q1463Q & Heterozygous & & & & & & & & & \\
\hline \multirow[t]{3}{*}{46} & $\begin{array}{l}\text { c. } 204099 A> \\
\text { C }\end{array}$ & Homozygous & \multirow{3}{*}{$\begin{array}{l}\text { Less } \\
\text { than } 5 \\
\text { years }\end{array}$} & \multirow[t]{3}{*}{0,33} & \multirow[t]{3}{*}{84,5} & Haemophilus spp & \multirow{3}{*}{\multicolumn{3}{|c|}{ Patient less than 5 years }} & \multirow[t]{3}{*}{-} & \multirow[t]{3}{*}{-} \\
\hline & $\begin{array}{l}\text { C. } 206359 \text { C > } \\
\text { A }\end{array}$ & Homozygous & & & & Moraxella spp & & & & & \\
\hline & M470V & Heterozygous & & & & & & & & & \\
\hline
\end{tabular}

This type of infection accelerates lung-function deterioration and increases the cost of treatments [40, 41]. In our results, $P$. aeruginosa was detected in $12.5 \%$ of airway cultures, and those patients were treated immediately with a double regimen of broad-spectrum intravenous (IV) antibiotics.

An important finding of our report was the presence of the H609R variant (caused by the transition of adenosine to guanine at nucleotide 1958 - exon 13). To our best knowledge, this type of variant has only been reported among Andeans' offspring, as a likely damaging variant [27, 42-44]. Among the 13 patients (38.23\%) with a complete sequence, only two patients displayed a homozygous state, while six had a compound heterozygous profile with the presence of the F508del variant [27, 44].

The other variants had been previously described in Ecuadorian patients with CF [27, 44]. Nefzi et al. analyzed Latin American CF patients and found four common variants: F508del (31.37\%), G542X (1.96\%), G85E (1.96\%) and N1303K (1.96\%), with $63.7 \%$ of Ecuadorian CF variants remaining unidentified [42]. In the second report, in order of frequency, the variants reported were F508del (37.1\%), G85E (8.9\%), G542X (2.4\%), N1303K (2.4\%), with a detection rate of $53.22 \%$ of the total of CF patients studied. All four of these variants were found in our tested patients in the following detection percentage: $52.77,5.56,11.11$, and $11.11 \%$, respectively.

CFTR exhibits an important allelic heterogeneity, a situation in which different variants in the same gene produce variations in clinical manifestations, with this heterogeneity known to be related to ethnic origin, as we can exemplify with H609R variant which has only reported in Hispanic offspring [27, 42-44]. The other common variants G542X, G85E and N1303K have been consistently found in Ecuadorian patients, with frequencies greater than that of Caucasian variant panels.

In seven of the patients, the polymorphism c.204099A > $\mathrm{C}$ was reported, all in homozygous state, this polymorphism has been reported only in Ecuadorian populations [27], with most of these patients also showing known pathological variants. This combination of polymorphisms and variants show a variety of phenotypes in patients, such as nutritional compound, microbiological cultures, respiratory spirometry values or as a combined effect. As Polizzi et al. described, there is a direct relation between phenotype with the specific variant panel [45]. The most severe cases with c.204099A > C polymorphism were between 10 and 15 years old and related to H609R and F508del/W1098X variants. In one of these patients, a poor nutrition status was seen, and in the second there were complications associated with respiratory deterioration. In addition, Moya et al. found in H609R homozygous Ecuadorian patients a severe clinical presentation of CF [44]. This contrasts with our first patient that had a heterozygous alteration with an important nutritional implication. Sebro et al. described F508del in the heterozygous compound, which showed a statistical association between variant and sweat chloride level, pancreatic function and Pseudomonas infection risk [46], also seen in our study. Finally, CFTR2 databases describe that patients with the W1098X variant have a predictive value in the range 62$100 \%$ [47], which was also present in our patient. The previous studies did not include patients that were included in this study, as it was confirmed with the patient and their carers that participation in past studies had not taken place. 
In four of our patients, the polymorphism c.206359C > A was reported in homozygous state. All were related to F508del/W1098X, G85E/H609R, and G970S variants, however, the first case was described in combination with c.204099A > C polymorphism as opposed to c.206359C > A. In the second patient, there was no marked nutritional alteration, with sweat testing measures showing a low value, the respiratory function was partially conserved, and only one hospital admission was seen. Decaesteker et al. describe that patients with G85E had a significantly higher sweat chloride, higher prevalence of pancreatic insufficiency, worse current weight for height and higher prevalence of chronic $P$. aeruginosa colonization. However, these findings are not highly concordant with our patient [45]. The last case demonstrated slight malnutrition, common bacteria colonization for the age and normal respiratory function. Therefore, there was phenotypic concordance, but there were no studies available about the clinical involvement of G970S variant in the available literature.

During genetic analysis there was a unique case with variant c.204099A >C and c.206359C > A in combination with benign polymorphism M470V. This patient showed only sweat test positive, but there was no malnutrition, microbiological alteration nor complications during the study period. However, sequential spirometry test results were unavailable due to the participant's age. M470V has been described as a benign polymorphism with slight respiratory problems and recurrence, which does not show on positive on sweat test [48]. The unique presence of that polymorphism combination (c.204099A > C, c.206359C > A and 470 V), in addition to the unexpected positive sweat test, make this case a unique opportunity for further investigation and followup in order to find more information about its phenotype expression, its management and its prognosis.

\section{Bias}

Selection bias was present as only cases who gave informed consent were included. Every eligible pediatric CF patient was approached; however only those patients that agreed alongside parents or guardians who agreed to participate were involved in the study. This was a single location study, so results may not generalizable for the whole Ecuadorian population. Information bias was reduced by using standardized medical records from the hospital, which were reviewed by two researchers to reduce any errors in reporting and were transcribed in two different databases that later were reconciled. Any discrepancies between the two reviewers were escalated to the study lead researcher for a resolving discussion. Diagnostic bias was reduced through only including patients with a confirmation of CF through a positive sweat test as well as genetic confirmation in the study.

\section{Limitations}

This study was not exempt from limitations. Patients were sampled from one hospital in Ecuador; therefore, a complete extrapolation to the entire Ecuadorian population might be inaccurate. To have a better understanding of the clinical, genetic and microbiological features of CF in Ecuador, a larger sample size, over multiple hospitals around the country would be needed. Another limitation was the access to funding and equipment. Due to the lack of resources and finance, only 36 of the 47 patients underwent a genetic analysis, a selection that was allocated on a first-come, first-served basis, a decision made according to the presence of available funding. In addition, the lack of a quality asthma research center made it difficult for doctors to test for bronchial hypersensitivity according to international standards, tests that would have been valuable for this type of research.

\section{Conclusions}

To our best knowledge, this is the first study exploring the clinical, genetic and bacteriological profile of CF's patients in Ecuador. Due to the lack of universal screening in the country, a large proportion of individuals are being diagnosed or misdiagnosed later than expected, jeopardizing their treatments and prognosis. The bacteriological results demonstrated that $S$. aureus was the most common pathogen found within the cultures, most of them showing susceptibility to sulfas, vancomycin, linezolid and ciprofloxacin.

Lastly, the current cohort of patients showed an important and unique genetic feature characterized by the presence of the g.204099A $>\mathrm{C}$ and the c.206359C $>\mathrm{A}$ homozygous polymorphism, as well as the presence of the H609R variant, a mutation only reported among Andeans dwellers.

\section{Abbreviations \\ BMI: Body Mass Index; CF: Cystic Fibrosis; CFTR: cystic fibrosis transmembrane regulator; dbSNP: Single Nucleotide Polymorphism Database; EMR: Electronic Medical Records; FEV : Forced Expiratory Volume in One Second; FVC: Forced Vital Capacity; HCAM: Carlos Andrade Marin Hospital; HIC: High Income Countries; IESS: Ecuadorian Institute of Social Security; IV: Intravenous; LMIC: Low- and Middle-Income Countries; PCR: Polymerase Chain Reaction; REGLAFQ: Registro Latinoamericano de Fibrosis Quistica; SK: Shwachman - Kulczycki}

\section{Acknowledgements}

We would like to thank Netlab in Ecuador for providing genetic testing at no cost to some of the patients who were not able to afford it.

\section{Authors' contributions}

Researcher YLV developed the specific study idea, she conducted the clinical interviews, and she was fully in charge of the follow-up. She was fully responsible for retrieving information from the health records. EOP acted as project lead and was responsible for the conceptualization of the manuscript, preliminary data analysis and wrote the primary draft of the manuscript. LGB and KSR performed the statistical and data analysis, created the tables and figures and contribute with the final draft of the manuscript. EV was responsible for interpreting some of the information from the medical records as 
well as interpret bacteriological reports while AL assisted in the structuring of this information within the report. EV and AL also contributed to the structuring of the final draft of the manuscript. EAE was responsible for interpreting the genetic results and for writing them down in the manuscript. GFP was responsible for the critical review of the manuscript, the final draft of the text, and he provided critical inputs on the interpretation of the overall results and the elaboration of the manuscript. The authors read and approved the final manuscript

\section{Funding}

The publication fee for this manuscript was paid by the Research Department of Universidad de las Americas, Quito, Ecuador.

\section{Availability of data and materials}

The datasets used during the current study are available from the corresponding author on reasonable request. His email is e.ortizprado@gmail. com.

\section{Ethics approval and consent to participate}

The study was approved by the Institutional Review Board at HCAM through the Quipux System with the number No.- HECAM-10-2018-00\#\#. The study participants were patients who received medical care at the hospital, and all of the information was anonymized for this publication. The patients received the standard of care for children with CF and written informed consent was routinely obtained from their parents when performing genetic testing and pulmonary function tests.

\section{Consent for publication}

Not applicable.

\section{Competing interests}

The authors declare that they have no competing interests.

\section{Author details}

${ }^{1}$ Pediatric Pneumology Service, Pediatric Unit of the Carlos Andrade Marin Specialties Hospital, Quito, Ecuador. ${ }^{2}$ One Health Research Group, Universidad de Las Americas, José Queri and Av. de los Granados, Quito, Ecuador. ${ }^{3}$ Faculty of Medicine, University of Southampton, Southampton, England. ${ }^{4}$ Genetics Department, Gynemedic, Mexico City, Mexico. ${ }^{5}$ Division of Pulmonary and Sleep Medicine, Children's National Health System, Washington, DC, USA.

\section{Received: 20 July 2019 Accepted: 27 February 2020}

\section{Published online: 06 March 2020}

\section{References}

1. Riordan JR, Rommens JM, Kerem B, Alon N, Rozmahel R, Grzelczak Z, et al. Identification of the cystic fibrosis gene: cloning and characterization of complementary DNA. Science. 1989;245(4922):1066-73.

2. Knowlton RG, Cohen-Haguenauer O, Van Cong N, Frézal J, Brown VA, Barker $D$, et al. A polymorphic DNA marker linked to cystic fibrosis is located on chromosome 7. Nature. 1985;318(6044):380.

3. Zielenski J, Rozmahel R, Bozon D, Kerem B, Grzelczak Z, Riordan JR, et al. Genomic DNA sequence of the cystic fibrosis transmembrane conductance regulator (CFTR) gene. Genomics. 1991;10(1):214-28.

4. Bobadilla JL, Macek M, Fine JP, Farrell PM. Cystic fibrosis: a worldwide analysis ofCFTR mutations?Correlation with incidence data and application to screening. Human Mutation junio de. 2002;19(6):575-606.

5. Stallings VA, Stark $\amalg$, Robinson KA, Feranchak AP, Quinton $H$, On growth $C P G$, et al. Evidence-based practice recommendations for nutrition-related management of children and adults with cystic fibrosis and pancreatic insufficiency: results of a systematic review. J Am Diet Assoc. 2008;108(5): 832-9.

6. Feigelson J, Anagnostopoulos C, Poquet M, Pecau Y, Munck A, Navarro J. Liver cirrhosis in cystic fibrosis-therapeutic implications and long term follow up. Arch Dis Child. 1993;68(5):653-7.

7. Ratjen F, Bell SC, Rowe SM, Goss CH, Quittner AL, Bush A. Cystic fibrosis. Nature Reviews Disease Primers May. 2015;1:15010.

8. Spoonhower KA, Davis PB. Epidemiology of cystic fibrosis. Clin Chest Med. 2016;37(1):1-8.
9. Davis PB. Cystic fibrosis since 1938. Am J Respir Crit Care Med. 2006;173(5): 475-82.

10. Potter BK, Khangura SD, Tingley K, Chakraborty P, Little J. Translating raredisease therapies into improved care for patients and families: what are the right outcomes, designs and engagement approaches in health-systems research? Genet Med. February 2016;18(2):117-23.

11. McCabe $L L$, Therrell BL, McCabe ERB. Newborn screening: rationale for a comprehensive, fully integrated public health system. Mol Genet Metab. 2002;77(4):267-73.

12. Tuchman LK, Schwartz LA, Sawicki GS, Britto MT. Cystic fibrosis and transition to adult medical care. PEDIATRICS. March 2010;125(3):566-73.

13. Stephenson AL, Sykes J, Stanojevic S, Quon BS, Marshall BC, Petren K, et al. Survival comparison of patients with cystic fibrosis in Canada and the United States. Ann Intern Med. 2017;166(8):537.

14. Quittner AL, Schechter MS, Rasouliyan L, Haselkorn T, Pasta DJ, Wagener JS. Impact of socioeconomic status, race, and ethnicity on quality of life in patients with cystic fibrosis in the United States. Chest. March 2010;137(3):642-50.

15. Goss CH, Sykes J, Stanojevic S, Marshall B, Petren K, Ostrenga J, et al. Comparison of nutrition and lung function outcomes in patients with cystic fibrosis living in Canada and the United States. Am J Respir Crit Care Med. March 2018:197(6):768-75.

16. Kabra SK, Kabra M, Shastri S, Lodha R. Diagnosing and managing cystic fibrosis in the developing world. Paediatr Respir Rev. 2006;7:S147-50.

17. Óscar FC. Avances en fibrosis quística. Revista Médica Clínica Las Condes. 2011;22(2):150-9.

18. Knapp EA, Fink AK, Goss CH, Sewall A, Ostrenga J, Dowd C, et al. The Cystic Fibrosis Foundation patient registry. Design and methods of a National Observational Disease Registry. Ann Am Thorac Soc. 2016;13(7):1173-9.

19. Keogh RH, Szczesniak R, Taylor-Robinson D, Bilton D. Up-to-date and projected estimates of survival for people with cystic fibrosis using baseline characteristics: a longitudinal study using UK patient registry data. J Cyst Fibros. March 2018;17(2):218-27.

20. Burgel P-R, Bellis G, Olesen HV, Viviani L, Zolin A, Blasi F, et al. Future trends in cystic fibrosis demography in 34 European countries. Eur Respir J. July 2015;46(1):133-41.

21. Martínez M. Fibrosis quística en Ecuador. Neumologia Pediatrica. 2010:5(1): 51.

22. Zolin A, Bossi A, Cirilli N, Kashirskaya N, Padoan R. Cystic Fibrosis Mortality in Childhood. Data from European Cystic Fibrosis Society Patient Registry. Int J Environ Res Public Health [Internet]. 2018 [Cited 28 October 2019];15(9). Available at: https://www.ncbi.nlm.nih.gov/pmc/articles/PMC6163251/.

23. Silva Filho LVRF, Castaños C, Ruíz HH. Cystic fibrosis in Latin America-improving the awareness. J Cyst Fibros. 2016;15(6):791-3.

24. Valle ÉP, Burgos RI, Valle JR, Egas Béjar D, Ruiz-Cabezas J-C. Analysis of CFTR gene mutations and Cystic Fibrosis incidence in the Ecuatorian population. Investigacion clinica. 2007;48(1)

25. Paz-Y-Miño C, Guillen Sacoto MJ, Leone PE. Genetics and genomic medicine in Ecuador. Mol Genet Genomic Med. 2016:4(1):9-17.

26. González-Andrade F. Standardized clinical criteria and sweat test combined as a tool to diagnose Cystic Fibrosis. Heliyon. 2018;4(12):e01050.

27. Ortiz SC, Aguirre SJ, Flores S, Maldonado C, Mejía J, Salinas L. Spectrum of CFTR gene mutations in Ecuadorian cystic fibrosis patients: the second report of the p.H609R mutation. Mol Genet Genomic Med. 2017;5(6):751-7.

28. Wagener J, Elkin E, Pasta D, Schechter M, Konstan M, Morgan W. Pulmonary function outcomes for assessing cystic fibrosis care. J Cyst Fibros. 2015;14(3): 376-83.

29. Farrell PM, Rosenstein BJ, White TB, Accurso FJ, Castellani C, Cutting GR, et al. Guidelines for diagnosis of cystic fibrosis in newborns through older adults: Cystic Fibrosis Foundation consensus report. J Pediatr. 2008;153(2): S4-14.

30. Farrell PM, White TB, Ren CL, Hempstead SE, Accurso F, Derichs N, et al. Diagnosis of cystic fibrosis: consensus guidelines from the Cystic Fibrosis Foundation. J Pediatr. 2017;181:S4-S15.

31. Gale S, Sabillón M, Ortega Iglesias JC. Caracterización de los pacientes con Fibrosis Quística diagnosticados por cloruros en Sudor. Act Ped Hond. 2017; 6(2):486-92.

32. Culhane S, George C, Pearo B, Spoede E. Malnutrition in cystic fibrosis: a review. Nutr Clin Pract. 2013;28(6):676-83.

33. Stollar F, Villac F, Cunha M, Leone C, Rodrigues J. Shwachman-Kulczycki score still useful to monitor cystic fibrosis severity. Clinics (Sao Paulo). 2011; 66(6):979-83. 
34. Olivo P, Flores $\mathrm{O}$, Rosero C. Correlación de los valores espirométricos con el puntaje clínico de Shwachman y elpuntaje radiológico de Brasfield, en la evaluación a pacientes con diagnóstico de fibrosis quística, atendidos en consulta externa del Hospital "Eugenio Espejo" de Quito, año 2014. Rev Fac Cien Med. 2014;39(2):25-30.

35. Kent B, Lane S, Van Beek E, Dodd J, Costello R, Tiddens H. Asthma and cystic fibrosis: a tangled web. Pediatr Pulmonol. 2014;49(3):205-13.

36. Weinberger M, Abu-Hasan M. Pseudo-asthma: when cough, wheezing, and dyspnea are not asthma. Pediatrics. 2007;120(4):855-64.

37. Cystic Fibrosis Foundation. Cystic Fibrosis Foundation Patient Registry 2017 Annual Data Report. Bethesda, Maryland; 2017.

38. Nixon GM, Armstrong DS, Carzino R, Carlin JB, Olinsky A, Robertson CF, et al. Clinical outcome after early Pseudomonas aeruginosa infection in cystic fibrosis. J Pediatr. 2001;138(5):699-704.

39. Emerson J, Rosenfeld M, McNamara S, Ramsey B, Gibson RL. Pseudomonas aeruginosa and other predictors of mortality and morbidity in young children with cystic fibrosis. Pediatr Pulmonol. 2002;34(2):91-100.

40. Baumann U, Stocklossa C, Greiner W, von der Schulenburg J-MG, von der Hardt H. Cost of care and clinical condition in paediatric cystic fibrosis patients. J Cyst Fibros. 2003;2(2):84-90.

41. Doring G, Conway SP, Heijerman HG, Hodson ME, Hoiby N, Smyth A, et al. Antibiotic therapy against Pseudomonas aeruginosa in cystic fibrosis: a European consensus. Eur Respir J. 2000;16(4):749-67.

42. Schrijver I, Pique L, Graham S, Pearl M, Cherry A, Kharrazi M. The Spectrum of CFTR variants in nonwhite cystic fibrosis patients: implications for molecular diagnostic testing. J Mol Diagnostics. 2016;18(1):39-50.

43. Keyeux G, Rodas C, Bienvenu T, Garavito P, Vidaud D, Sanchez D, et al. CFTR mutations in patients from Colombia: implications for local and regional molecular diagnosis programs. Hum Mutat. 2003;22(3):259.

44. Moya-Quiles MR, Glover G, Mondéjar-López P, Pastor-Vivero MD, FernándezSánchez A, Sánchez-Solís M. CFTR H609R mutation in Ecuadorian patients with cystic fibrosis. J Cyst Fibros. 2009;8(4):280-1.

45. Polizzi A, Tesse R, Santostasi T, Diana A, Manca A, Logrillo VP, et al. Genotype-phenotype correlation in cystic fibrosis patients bearing [H939R: H949L] allele. Genet Mol Biol. 2011;34(3):416-20.

46. Sebro R, Levy H, Schneck K, Dimmock D, Raby BA, Cannon CL, et al. Cystic fibrosis mutations for p.F508del compound heterozygotes predict sweat chloride levels and pancreatic sufficiency. Clin Genet. 2012;82(6):546.

47. CFTR2 Variant Search / CFTR2 [Internet]. [Cited 28 October 2019]. Available at: https://www.cftr2.org/mutation/general/W1098X/.

48. Çelik T, Güneşaçar R, Balcı A, Ünal S, Aldic G, Eskici H, et al. The Importance of the M470V Polymorphism. BUCH [Internet]. 2017 [Cited 28 October 2019]; Available at: http://www.behcetuzdergisi.com/jvi.asp?pdir=behcetuz\&plng= eng\&un=BUCHD-59254\&look4=.

\section{Publisher's Note}

Springer Nature remains neutral with regard to jurisdictional claims in published maps and institutional affiliations.

\section{Ready to submit your research? Choose BMC and benefit from:}

- fast, convenient online submission

- thorough peer review by experienced researchers in your field

- rapid publication on acceptance

- support for research data, including large and complex data types

- gold Open Access which fosters wider collaboration and increased citations

- maximum visibility for your research: over $100 \mathrm{M}$ website views per year

At BMC, research is always in progress.

Learn more biomedcentral.com/submissions 